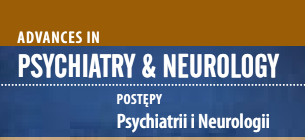

Correspondence to/Adres do korespondencji:

Dr Jakub M. Antczak

Department of Clinical Neurophysiology

Institute of Psychiatry and Neurology

9 Sobieskiego St.

02-957 Warsaw, Poland

e-mail: jacob.antczak@gmail.com

Submitted/Otrzymano: 22.07.2021

Accepted/Przyjęto do druku: 13.09.2021

\section{Transcranial magnetic stimulation as a diagnostic and therapeutic tool in cerebral palsy}

\author{
Przezczaszkowa stymulacja \\ magnetyczna jako diagnostyczne \\ i terapeutyczne narzędzie \\ w dziecięcym porażeniu mózgowym
}

\author{
Jakub M. Antczak \\ Department of Neurology, Jagiellonian University Medical College, Krakow, Poland \\ Department of Clinical Neurophysiology, Institute of Psychiatry and Neurology, \\ Warsaw, Poland
}

\begin{abstract}
Purpose: Cerebral palsy (CP) is one of the leading causes of child disability, which profoundly affects the lives of whole families and contributes to the burden of health care. Despite the extensive rehabilitative, surgical and other therapeutic efforts of an array of specialists, a significant proportion of patients remain severely disabled. Transcranial magnetic stimulation (TMS) is a non-invasive diagnostic tool in various diseases of the cerebral cortex and cortico-spinal tract (CST). Repetitive TMS (rTMS) is able to induce a long-lasting cerebral plasticity, which is associated with a therapeutic effect in a number of psychiatric and neurological diseases. This article reviews the diagnostic findings gained with TMS in CP as well as therapeutic trials performed with rTMS.

Views: The absence of responses in the motor cortex in the first months of life, as revealed by TMS, may predict the development of $\mathrm{CP}$ in children at risk. In a proportion of children with the unilateral form of CP, TMS documents the pathological preservation of ipsilateral, cortico-spinal connections from the non-lesioned hemisphere, which is associated with poor outcome.

rTMS seems to be a safe method with significant therapeutic potential in CP. The data published so far reveals an almost unanimously significant therapeutic benefit in motor performance over placebo. However, the studies conducted to date have almost without exception involved children with unilateral palsy, and have focused nearly exclusively on therapy for motor symptoms.

Conclusions: Magnetic stimulation brings significant diagnostic and therapeutic effects in CP. However, more studies that go beyond the limits specified above are still awaited.
\end{abstract}

Key words: transcranial magnetic stimulation, cerebral palsy, ispilateral connections, motor improvement.

\title{
Streszczenie
}

Cel: Mózgowe porażenie dziecięce (MPD) to jedna z wiodących przyczyn niepełnosprawności wśród dzieci. Obecność MPD drastycznie zmienia ich życie oraz życie ich rodzin, a także jest znacznym obciążeniem dla opieki zdrowotnej. Pomimo zharmonizowanych wysiłków rehabilitacyjnych, chirurgicznych oraz innego rodzaju zabiegów terapeutycznych, przeprowadzanych przez wielu specjalistów, znaczna część dzieci pozostaje trwale i głęboko niepełnosprawna. Przezczaszkowa stymulacja magnetyczna (transcranial magnetic stimulation - TMS) jest nieinwazyjną metodą diagnostyczną w różnych schorzeniach kory mózgowej i dróg korowo-rdzeniowych. TMS serią bodźców (repetitive TMS - rTMS) jest metodą długotrwałej indukcji plastyczności mózgu i przynosi efekt terapeutyczny w wielu chorobach psychicznych i neurologicznych. W pracy omówiono wyniki diagnostycznego zastosowania TMS w MPD oraz badania nad terapeutycznym wykorzystaniem rTMS w MPD.

Poglądy: Brak odpowiedzi ruchowej po stymulacji nad korą ruchową w pierwszych miesiącach życia może mieć wartość predykcyjną co do rozwoju DPM u dzieci z czynnikami ryzyka. U części dzieci z połowiczą postacią MPD za pomocą TMS udokumentowano patologiczne przetrwanie ipsilateralnych połączeń korowo-rdzeniowych z półkuli niedotkniętej uszkodzeniem, które jest związane ze znaczną niesprawnością ruchową. Metoda rTMS wydaje się techniką bezpieczną, mającą istotny potencjał terapeutyczny w DPM. Dotychczas opublikowane dane niemal jednomyślnie potwierdzają istotne korzyści terapeutyczne dla sprawności ruchowej w porównaniu z placebo. Badania przeprowadzone do tej pory włączały jednak prawie wyłącznie dzieci z połowiczą formą porażenia oraz koncentrowały się prawie w całości na deficytach ruchowych. 
Wnioski: Stymulacja magnetyczna z dużym prawdopodobieństwem przynosi diagnostyczne i terapeutyczne korzyści w DPM. Konieczne są jednak dodatkowe badania, wychodzące poza ograniczenia wymienione powyżej.

Słowa kluczowe: przezczaszkowa stymulacja magnetyczna, dziecięce porażenie mózgowe, połączenia tożstronne, poprawa deficytów ruchowych.

\section{INTRODUCTION}

Cerebral palsy (CP) is one of the leading causes of child disability, which often persists into adulthood [1]. $\mathrm{CP}$ can manifest as tetra-, hemi- or paraplegia, movement disorders, cerebellar syndrome and other forms of motor impairment. A significant proportion of patients suffer additionally from epilepsy, cognitive disabilities, language and learning problems and behavioural changes [2]. All these symptoms may vary in severity, though $\mathrm{CP}$ usually brings significant disability to the child, affecting their life and that of the whole family dramatically. With epidemiology reaching 2.08 per 1000 live births [3], CP is also a significant social and healthcare burden. The main causes of $\mathrm{CP}$ occur before and during prenatal life and include systemic diseases, the effects of intoxicants, infections, impaired fertility of the mother during preconception and pregnancy, vaginal bleeding, placental malfunction, tocolytic drugs, oligohydramnios, polyhydramnios, intrauterine suppression, and intrauterine hypoxia. Peri-, neo- and postnatal causes account for 10 to $18 \%$ of cases. The most common of these causes are premature rupture of membranes, premature birth, infections, metabolic changes, and convulsions during the neonatal period [4]. The most frequent direct mechanism of development of $\mathrm{CP}$ is stroke [5]. Comprehensive motor rehabilitation is the most important therapy for CP. It is based on the concept of neuroplasticity, i.e. the capability of the brain to induce long-lasting functional and structural changes in response to specific stimuli. Treatment of spasticity often requires physiotherapy and pharmacotherapy, with baclofen and benzodiazepines for generalized effect [6] and botulinum toxin administered focally [7]. In severe cases, surgical assistance may be necessary. Complications related to $\mathrm{CP}$ are frequent and are treated by an array of specialists and procedures. Orthopedic correction is often needed for the hip joint and for deformities in other locations, and bisphosphonates are often given to maintain bone density. Seizures, which affect over a half of patients with $\mathrm{CP}$, require pharmacological control, frequently with several antiepileptic drugs [8-12]. Further management of $\mathrm{CP}$ also involves speech therapy, training of cognitive functions, psychotherapy for the child and family, and the management of bedsores and pain [13], as well as therapy for feeding difficulties [14]. Even in the populations and areas where access to comprehensive therapy is well provided, the motor and other disabilities associated with $\mathrm{CP}$ are frequent and often severe. In general, $30 \%$ of patients with $\mathrm{CP}$ are wheelchair-bound. A similar proportion is severely intellectually impaired, $10 \%$ have severe visual impairment, $20 \%$ have active seizures [15] and over 50\% have problems with speech [16]. Overall motor and other disability related to CP remains a significant burden for affected individuals, their families, and for the society.

One of the newer diagnostic and therapeutic options with the potential to improve $\mathrm{CP}$ outcomes is transcranial magnetic stimulation (TMS). This method belongs to the array of modalities of non-invasive brain stimulation, in which the brain is stimulated directly with physical forces but without the need for surgery or general anesthesia. In TMS, brief, time-varied magnetic field pulses, of an intensity up to $2 \mathrm{~T}$, are generated in a coil held directly over the scalp. The magnetic field passes through scalp and skull with negligible attenuation and reaches the cerebral cortex. Due to the relatively good electroconductivity of the cortex, the magnetic field induces the electric current which in turn depolarizes the neurons. Depolarization takes place only in the area of the cortex beneath the coil. The magnetic field abates exponentially with the distance from the coil and is too weak to induce a significant electric current in the subcortical structures, as well as the cortical areas located remotely from the coil [17]. A TMS stimulator may generate single- or paired pulses, or may elicit magnetic pulses in series. The first two of these modalities are used mainly for diagnostic purposes and the third, called repetitive transcranial magnetic stimulation (rTMS), is used mainly for therapy. Single pulses enable the assessment of cortical excitability and conduction in the corticospinal tract. The excitation of primary motor areas (PMA) induces volleys that descend down the central and peripheral motor pathways and finally results in the contraction of respective skeletal muscles, which can be recorded with superficial electrodes as motor evoked potential (MEP) with equipment and techniques similar to those used in nerve conduction studies. The recording of MEPs allows for the estimation of the motor threshold (MT), which is the lowest intensity of magnetic field capable of reliably inducing MEPs. TMS with single pulses also allows the assessment of intracortical inhibition by recording the cortical silent period (CSP). CSP is a brief involuntary relaxation of the con- 
Transcranial magnetic stimulation as a diagnostic and therapeutic tool in cerebral palsy

Przezczaszkowa stymulacja magnetyczna jako diagnostyczne i terapeutyczne narzędzie w dziecięcym porażeniu mózgowym

tracted muscle which directly follows the MEP. In normal individuals it should last between 100 and 200 milliseconds and it is thought to be mediated mainly by intracortical GABAergic transmission. Finally, performing TMS in a single pulse mode and coupled with a neuronavigation system enables the functional mapping of PMA [18].

TMS with paired pulses applies two pulses separated by a short time interval. The pulses differ in their intensity. The first is called the conditioning pulse and it modulates (i.e. decreases or increases) the amplitude of the MEP obtained after the second, i.e. the test impulse. The direction and the magnitude of this modulation depends on the time separating both stimuli, the intensity of the conditioning stimulus, and its location. There are many paradigms of the use of paired pulse simulation used for clinical purposes and in neuroscience. Patients with $\mathrm{CP}$ were investigated with three of them, namely with short interval cortical inhibition (SICI), intracortical facilitation (ICF), and with interhemispheric inhibition (IHI). In SICI the conditioning stimulus has subthreshold intensity and precedes the test stimulus by one- to-four milliseconds. The amplitude of MEP, evoked by the test stimulus, will decrease in a healthy subject up to $40 \%$ (with respect to the amplitude of MEP evoked by the same test stimulus but without the preceding conditioning stimulus). SICI is closely related to GABAergic transmission, involving mainly GABA-A neurons within the motor cortex [19]. The prolongation of the interstimulus interval over $7 \mathrm{~ms}$ and up to $20 \mathrm{~ms}$ will induce ICF, with an increase in the MEP amplitude which may even quadruple. ICF is related to glutaminergic transmission [20,21]. Finally, interhemispheric inhibition (IHI) can be measured by applying the conditioning stimulus to the PMA contralateral to the PMA, stimulated by the test stimulus with an interval ranging from 6 to $50 \mathrm{~ms}$, which will decrease the amplitude of MEP in healthy subjects [22].

\section{Repetitive transcranial magnetic stimulation}

rTMS uses a series of magnetic stimuli which repetitively depolarize the targeted neurons. Repetitive depolarization induces synaptic plasticity: high frequencies of depolarization i.e. $\geq 5 \mathrm{~Hz}$ will predominantly induce long term facilitation (LTF) with an increase in local metabolic rate, synaptic transmission and enhancement of activity of the related brain circuits. On the contrary, low frequency rTMS i.e. $\leq 1 \mathrm{~Hz}$ will result mainly in long term depression (LTD) with a decrease in metabolic rate and transmission [23]. Magnetic stimuli can be also elicited in a more complex way than the constant frequency. The most frequently used excitatory pattern is called intermittent theta burst (iTBS), whereas the inhibitory pattern is the continuous theta burst (cTBS). These protocols usually need fewer stimuli and much less time to achieve similar neurophysiological and often also clinical effects than stimulation with constant frequency.
However, they still provide significantly less evidence of therapeutic efficacy [24]. A single rTMS session, which may consist of several hundred to several thousand stimuli, induces changes which outlast the stimulation for minutes, hours or, occasionally, days. Repeating the sessions, once daily or several times a day, will consolidate the effect, which may last for weeks or months. Such a longlasting modification of brain activity may be associated with therapeutic benefits. In depression, enhancing the activity of the left dorsolateral prefrontal cortex (DLPFC) with high frequency, rTMS or decreasing the activity of the right DLPFC with low frequency rTMS, reinstalls the balance between the frontal areas and other regions, which improves mood and other symptoms, even in drug-resistant patients $[25,26]$. High frequency stimulation over the frontal areas and over the precuneus helps to preserve and even to improve cognitive functions in various types of dementia and mild cognitive impairment [27-32]. Stimulation of the motor cortex can induce an analgesic effect in neuropathic pain due to its antidromic excitation of thalamocortical connections [33,34]. Other evidenced therapeutic effects include improvement of spasticity in multiple sclerosis, suppression of epileptic activity of the epileptic foci, alleviation of tinnitus, alleviation of auditory hallucinations in schizophrenia, and others [24].

\section{Transcranial magnetic stimulation findings and therapy in adult stroke}

In acute stroke MT is increased, reflecting the loss of a proportion of excitable motor neurons [35, 36]. MEPs are low or absent on the affected side. If present, they predict good recovery [37-40]. The contralateral MEPs from the unaffected hemisphere increase, representing overactivity [41-43]. SICI is reduced on the affected and possibly also on the unaffected side, reflecting disinhibition due to impairment of GABAergic transmission [44]. rTMS improves post-stroke weakness, neglect and aphasia [45]. Usually, rTMS is performed over the contralesional motor cortex at low frequency, which inhibits the pathologic overactivity of the non-lesioned hemisphere, which in turn creates more space for the lesioned cortex to reorganize its connections and renew its function. A number of trials have also used the high frequency in the lesioned PMA, which activated the neurons that survived the stroke and thus helped to restore function. Some used cTBS and iTBS over the non-lesioned and lesioned hemispheres respectively [24]. In CP, TMS findings and therapeutic protocols with rTMS will parallel to some degree those in adults with stroke. On the other hand, significant differences are present which should be considered when performing magnetic stimulation in a patient with CP. Moreover, as the TMS has been done in children for a markedly shorter period of time, the amount of evidence and number of findings are still low. These issues, 
as well as other aspects of the current knowledge about diagnostic and therapeutic efficacy of magnetic stimulation in $\mathrm{CP}$, are presented below.

\section{VIEWS}

This review was conducted following the Scale for the Assessment of Narrative Review Articles [46]. We included clinical studies regarding: (1) the use of TMS parameters to assess cortical excitability and motor pathways in $\mathrm{CP}$, and (2) the use of repetitive TMS in the treatment of CP. We searched the electronic databases of MEDLINE through Pub-Med (United States National Library of Medicine, Bethesda, Maryland, USA) for relevant research articles published up to March 2021. The search strategy consisted of the following terms used in combination: "transcranial magnetic stimulation", "TMS", "cerebral palsy", "perinatal stroke". Additional searches of the references of the retrieved manuscripts were also conducted in order to collect information about additional relevant literature.

\section{Transcranial magnetic stimulation findings in patients with cerebral palsy}

In general, studies using TMS and rTMS in CP reported a lack of serious adverse events and good tolerance [47], even in children in their first year of life [48]. One of the main findings is the preservation of shortlatency and high amplitude ipsilateral MEPs after stimulation of the non-lesioned motor cortex in unilateral CP. According to studies on healthy infants, ipsilateral motor responses are present in the first months of life. They have comparable amplitudes and thresholds to the contralateral ones but significantly shorter latencies [49]. From the third month of life onwards ipsilateral corticospinal connections undergo withdrawal in competition with contralateral ones, so that in the second year ipsilateral MEPs should be significantly smaller and of longer latencies. Low amplitude MEPs of prolonged latency may be still evoked in normal adults as the small proportion (8 to $15 \%)$ of the fibers of the cortico-spinal tract remains uncrossed [50]. Withdrawal of ipsilateral connections neither occurs, nor is hampered, if the contralateral motor cortex has been damaged in the pre-, peri- or postnatal period $[49,51]$. Moreover, persistent ipsilateral connections from the non-lesioned hemisphere seem to contribute to the gradual withdrawal of contralateral projections from the lesioned hemisphere which survived the perinatal damage, thus worsening the disability [52]. In accordance with these mechanisms, lack of contralateral MEPs after stimulation of lesioned PMA and well-preserved ipsilateral MEPs after stimulation of contralesional PMA, or the presence of both, predict poor motor outcome [53-61]. Moreover, the presence of ipsilateral MEPs of high am- plitude may predict the development of mirror movements - a form of involuntary movement typical in some patients with CP [62]. This is in contrast with lesions of PMA acquired at a post-infant age, which does not result in the appearance of high-amplitude ipsilateral responses of normal latency $[63,64]$. Studies using TMS and imaging suggest that the causes of the most severe abnormalities in MEPs are multicystic encephalomalacia as well as cortical and deep grey matter lesions $[65,66]$. While the persistence of ipsilateral MEPs is generally not a favorable factor, it seems that it may be overcome with intensive motor training. Such a conclusion results from the recent studies which have reported a lack of differences in motor improvement gained during intensive constraint-induced movement therapy (CIMT) and bimanual training between children with contralateral, ipsilateral, or bilateral corticospinal connections [67-69]. In a study of Juenger et al. (2013), the ipsilateral MEPs to the paretic hand decreased, along with the motor improvement of this hand achieved with CIMT [70]. These results indicate that the relation between corticospinal tract organization and the outcome may be more complex, and that some not-yet-discovered capacities of brain plasticity may be mobilized with the proper intensive training. Furthermore, a study by Marneweck et al. (2018), which used a neuronavigation system, indicated that the magnitude of cortical area on the non-lesioned side, in which bilateral MEPs can be evoked, correlates positively with the dexterity of the paretic hand (but, at the same time it correlates with the occurrence of the mirror movements) [71]. This may be an indication that ipsilateral connections from the non-lesioned cortex may have a multidirectional effect on the ipsilateral body side. Other finding gained with TMS and navigation is the topographic, lateral shift of somatotopic areas of the examined muscles in a proportion of patients $[72,73]$. The most likely interpretation of this finding is the recruitment of adjacent, spared cortical areas to overtake the motor control, which is a sign of high plastic capability of the developing brain. Of other relevant studies in patients with unilateral lesions, a number of clinical trials should be mentioned, which assessed the efficacy of motor rehabilitation - usually CIMT and bimanual training - and monitored its effect on the corticospinal tract along with changes in motor performance. These studies showed a constant reactivity of TMS parameters - usually in the form of an increase of the amplitude of contralateral MEP to motor rehabilitation [74-79]. Only a few studies applied TMS to infants in their first months of life $[48,80]$, yet the findings are probably of crucial importance: they revealed that the absence of contralateral MEPs after ipsilesional stimulation is associated with the development of atypical movements in the first year and a later diagnosis of CP. TMS may therefore be an useful tool with which to diagnose $\mathrm{CP}$ early; this would allow rehabilitation to be started in a timely manner, without 
Transcranial magnetic stimulation as a diagnostic and therapeutic tool in cerebral palsy

Przezczaszkowa stymulacja magnetyczna jako diagnostyczne i terapeutyczne narzędzie w dziecięcym porażeniu mózgowym

missing the period during which plasticity and therapeutic potential are at their peak.

Other documented changes in cortical excitability and function of corticospinal tract in children with unilateral lesions resemble, in general, changes seen in adult stroke: The contralateral MEP from the non-lesioned PMA tends to have higher amplitude and shorter latency, reflecting the hyperexcitability of the non-lesioned hemisphere (Eyre et al., 2001). SICI is decreased and ICF unaltered in CP [81]. The interhemispheric inhibition is altered or absent and MT is higher on the lesioned side [82-84].

Only two studies examined patients with spastic diplegia due to $\mathrm{CP}[72,85]$. In the first, the recording of MEP was limited to the right tibialis anterior and the shortening of CSP was the only difference to healthy volunteers. In the second, ipsilateral responses were found only in subjects who showed significant between-side differences of motor function.

\section{Repetitive transcranial magnetic stimulation as a therapeutic tool in cerebral palsy}

The first trials of rTMS in CP paralleled the most commonly used therapeutic protocol in adult stroke, which is low frequency rTMS over the non-lesioned motor cortex aimed at the suppression of its inhibitory impact on the lesioned PMA. Consistently with protocol selection, only hemiparetic children, usually of school age, were recruited $[55,86]$. Significantly, the studies revealed a better effect of rTMS on motor performance over placebo stimulation. Kirton et al. reported improved grip strength, and Gillick et al. on improvement in the Assisting Hand Assessment, a video recording based test in which 22 items evaluate the child's performance in tasks which require bimanual activity. The effect was, however, no more visible at six months follow up [87]. Importantly, Gillick et al. also measured sensory deficits with the 12-objects stereognosis test, in which children needed to recognize a maximal number out of 12 standardized objects, which were subsequently put into the affected hand; however, no improvement in the stereognosis was seen. The only partial effectiveness and lack of long-term effectivity shown in the study of Gillick et al. may be associated with the relatively low number of rTMS sessions involved (five), which in addition were administered every second day (on the alternate days, the CIMT was performed). The therapeutic advantage of a larger number of sessions was documented in the later study by Rajak et al., where improvement in the gross motor function measure was more prominent after 40 rather than 30 or 20 sessions [88]. The PLASTIC CHAMPS study (Plastic Adaptation Stimulated by TMS and Induced Constraint for Congenital Hemiparesis After Perinatal Stroke) is distinguished from the others as it involved a significantly bigger group $(n=45)$ receiving more intensive therapy: ten daily
rTMS sessions and the CIMT therapy covering 90\% of waking time [89]. Children received one, both or neither of these therapies. Receiving both therapies brought long-lasting improvement in the form of learning new motor skills, which was still present during the six months follow-up. The study also documented the effect of neuromodulation on excitability parameters: after the therapy, the amplitude of the MEPs evoked from the paretic muscles after stimulation over the lesional hemisphere increased and the SICI decreased. No changes were seen in ICF and IHI $[76,84]$.

With the exception of the first study on rTMS efficacy [55], in almost all other studies patients underwent rTMS (or sham rTMS) concurrently with motor rehabilitation. Technically, rehabilitation was performed directly after the rTMS session. One study compared the effect of rTMS alone vs. rTMS with occupational therapy. Two therapies combined brought significantly better improvement than rTMS alone [90].

While the study of Gillick et al. excluded patients in whom stimulation of ipsilesional PMA could not elicit MEP, the other studies did not. Their favorable results indicate that the lack of electrophysiologic confirmation of preserved integrity of lesioned motor pathways does not preclude a therapeutic response. In addition, the PLASTIC CHAMPS study revealed a lack of association of preserved MEP with the therapeutic efficacy of rTMS [89]. Only one trial included exclusively children with bilateral CP. It investigated the influence of rTMS on the disruption of the structural brain network, however, no effect on clinical signs was reported [91]. In another trial, children with bilateral CP along with unilateral paresis were recruited. In this study, rTMS with angulated coil, which probably covered the entire bilateral motor cortex, resulted in a decrease of spasticity [92]. While most of the studies measured only motor performance as the outcome, the study by Dadashi et al. also documented improvement in balance control [93]. One case report and one controlled trial assessed the effect of rTMS on cognitive performance in CP [94, 95]. In the first, the right DLPFC was stimulated with low $0.5 \mathrm{~Hz}$, and in the second the left DLPFC with high $10 \mathrm{~Hz}$, frequency. The case report was a six-year-old boy, who improved in the Gesell developmental diagnosis scales after eight months of rTMS administered once daily on all working days. Along with cognitive improvement, the repetitively and extensively studied fMRI showed a gradual increase in functional brain connectivity, especially within the precuneus and hippocampus, as well as between the default mode network, dorsal attention network, and insula network. In the second study, the effect of four weeks of stimulation on learning ability was compared with that of the standard rehabilitation for daily living activities with 15 children in each group. rTMS improved learning abilities, along with an increase 
in EEG alpha power and other electroencephalographic changes. However, no detailed comparison with the other group and no information regarding randomization and blinding were provided in the article.

\section{LIMITATIONS}

This review is not systematic and the quantification of the available data is not provided.

\section{CONCLUSIONS}

TMS provided insight into the organization of central motor pathways in patients with $\mathrm{CP}$, which is characterized by the preservation of ipsilateral projections from the non-lesioned PMA. Moreover, it documented the possibility that ipsilateral projections may competitively weaken contralateral ones, which may further worsen paresis. Ipsilateral connections are also related to the development of pathologic mirror movements. On the other hand, a domination of ipsilateral responses should not discourage rehabilitative efforts as such children may also gain significant functional improvement. Of particular significance for the management of $\mathrm{CP}$ are the few studies which have investigated infants in their first year of life and which documented the association of the absence of MEP with the later development of paresis. Performing TMS in the first months of life may therefore contribute to the early diagnosis of $\mathrm{CP}$ and to a timely initiation of rehabilitation.

An important conclusion resulting from the clinical trials with rTMS conducted to date is the general safety and good tolerance of this method among children with CP. This should encourage professionals in child neurology to introduce TMS into their practice and research. The general paucity of studies indicates that some lack of confidence regarding safety may persist even in academic centers. On the other hand, rTMS in children may bring particularly great benefits as the degree of plasticity is higher in the developing brain, especially during the first year of life [96]. In this light, most desperately lacking are trials on infants, which have not yet been done at all. The existing data were collected mainly on children in school and preschool age, and it seems to convincingly support the use of rTMS in $\mathrm{CP}$ in further research, and probably already in practice. Even if the number and heterogeneity of the available studies does not allow us to conduct a systematic review or meta-analysis of therapeutic efficacy, the result are moderately favorable in the majority of the trials. No study reported negative results, i.e. a lack of efficacy of rTMS, which is in striking contrast to the research made on adults. Further studies should certainly include more populations with bilateral palsy or paraparesis, which in terms of incidence exceed the patients with hemiplegic phenotype [97]. In connection with this remark, future clinical trials should also target the lesioned hemisphere with high frequencies or with other protocols inducing, mainly, long-term potentiation, such as iTBS. Experiences of work with adult patients with stroke indicate that the effects may be favorable [24]. In lesioned PMA, eliciting MEPs may be difficult or impossible and therefore in such trials the use of neuronavigation systems is advocated. This also concerns the use of rTMS for purposes other than motor rehabilitation, such as stimulation outside PMA. The few attempts that have been made indicate that rTMS may have potential in cognitive rehabilitation. No data exist on therapy for speech impairment, ataxia, or behavioural complications related to CP. Another possibility to extend the therapeutic potential of rTMS in CP is the simultaneous application of rTMS and motor rehabilitation, e.g. in form of virtual reality. Such a trial has already been successfully conducted with transcranial direct current stimulation - another modality of non-invasive brain stimulation [98]. The relatively strong sounds and sensory sensations which are associated with rTMS make simultaneous rehabilitation difficult, but the first studies in adults with dementia showed that such an approach is possible [99].

In summary, the work completed to date indicates TMS as a valuable tool for gaining insight into the pathophysiology of motor pathways in $\mathrm{CP}$, and for predicting early development of CP in children at risk. rTMS is a safe method of modulation of brain plasticity with promising results regarding its therapeutic efficacy in CP. Future studies should provide data that will help with the optimization of therapy, extend its application to not-yet investigated symptoms, and tailor the site and protocol of stimulation to particular phenotypic subgroups of CP.

\section{Conflict of interest/Konflikt interesu}

Absent./Nie występuje.

Financial support/Finansowanie

Absent./Nie występuje. 


\section{References/Piśmiennictwo}

1. Colver A, Fairhurst C, Pharoah PO. Cerebral palsy. Lancet 2014; 383: 1240-1249.

2. Rosenbaum P, Paneth N, Leviton A, Goldstein M, Bax M, Damiano D, et al. A report: the definition and classification of cerebral palsy April 2006. Dev Med Child Neurol Suppl 2007; 109: 8-14.

3. Oskoui M, Coutinho F, Dykeman J, Jetté N, Pringsheim T. An update on the prevalence of cerebral palsy: a systematic review and meta-analysis. Dev Med Child Neurol 2013; 55: 509-519.

4. Sadowska M, Sarecka-Hujar B, Kopyta I. Cerebral palsy: current opinions on definition, epidemiology, risk factors, classification and treatment options. Neuropsychiatr Dis Treat 2020; 16: 1505-1518.

5. Kirton A, Metzler MJ, Craig BT, Hilderley A, Dunbar M, Giuffre A, et al. Perinatal stroke: mapping and modulating developmental plasticity. Nat Rev Neurol 2021; 17: 415-432.

6. Quality Standards Subcommittee of the American Academy of Neurology and the Practice Committee of the Child Neurology Society, Delgado MR, Hirtz D, Aisen M, Ashwal S, Fehlings DL, McLaughlin J, et al. Practice parameter: pharmacologic treatment of spasticity in children and adolescents with cerebral palsy (an evidence-based review): report of the Quality Standards Subcommittee of the American Academy of Neurology and the Practice Committee of the Child Neurology Society. Neurology 2010; 74: 336-343.

7. Pin TW, Elmasry J, Lewis J. Efficacy of botulinum toxin A in children with cerebral palsy in Gross Motor Function Classification System levels IV and V: a systematic review. Dev Med Child Neurol 2013; 55: 304-313.

8. Hanci F, Türay S, Dilek M, Kabakuş N. Epilepsy and drug-resistant epilepsy in children with cerebral palsy: a retrospective observational study. Epilepsy Behav 2020; 112: 107357.

9. Tokatly Latzer I, Blumovich A, Sagi L, Uliel-Sibony S, Fattal-Valevski A. Prediction of drug-resistant epilepsy in children with cerebral palsy. J Child Neurol 2020; 35: 187-194.

10. Zelnik N, Konopnicki M, Bennett-Back O, Castel-Deutsch T, Tirosh E. Risk factors for epilepsy in children with cerebral palsy. Eur J Paediatr Neurol 2010; 14: 67-72.

11. Rahman MM, Akhter S, Karim BA. Epilepsy in children with cerebral palsy. Mymensingh Med J 2004; 13: 67-70.

12. Kułak W, Sobaniec W. Risk factors and prognosis of epilepsy in children with cerebral palsy in north-eastern Poland. Brain Dev 2003; 25: 499-506.

13. Green LB, Hurvitz EA. Cerebral palsy. Phys Med Rehabil Clin N Am 2007; 18: 859-882, vii.

14. Kuperminc MN, Stevenson RD. Growth and nutrition disorders in children with cerebral palsy. Dev Disabil Res Rev 2008; 14: 137-146.

15. Surveillance of Cerebral Palsy in Europe. Prevalence and characteristics of children with cerebral palsy in Europe. Dev Med Child Neurol 2002; 44: 633-640.

16. Darling-White M, Sakash A, Hustad KC. Characteristics of speech rate in children with cerebral palsy: a longitudinal study. J Speech Lang Hear Res 2018; 61: 2502-2515.

17. Hallett M. Transcranial magnetic stimulation: a primer. Neuron 2007; 55: 187-199.

18. Groppa S, Oliviero A, Eisen A, Quartarone A, Cohen LG, Mall V, et al. A practical guide to diagnostic transcranial magnetic stimulation: report of an IFCN committee. Clin Neurophysiol 2012; 123: 858-882.

19. Di Lazzaro V, Oliviero A, Profice P, Pennisi MA, Di Giovanni S, Zito G, et al. Muscarinic receptor blockade has differential effects on the excitability of intracortical circuits in the human motor cortex. Exp Brain Res 2000; 135: 455-461.

20. Kujirai T, Caramia MD, Rothwell JC, Day BL, Thompson PD, Ferbert A, et al. Corticocortical inhibition in human motor cortex. J Physiol 1993; 471: 501-519.

21. Ziemann U, Chen R, Cohen LG, Hallett M. Dextromethorphan decreases the excitability of the human motor cortex. Neurology 1998; 51: 1320-1324.

22. Schambra HM, Sawaki L, Cohen LG. Modulation of excitability of human motor cortex (M1) by $1 \mathrm{~Hz}$ transcranial magnetic stimulation of the contralateral M1. Clin Neurophysiol 2003; 114: 130-133.

23. Siebner HR, Rothwell J. Transcranial magnetic stimulation: new insights into representational cortical plasticity. Exp Brain Res 2003; 148: 1-16.

24. Lefaucheur JP, Aleman A, Baeken C, Benninger DH, Brunelin J, Di Lazzaro V, et al. Evidence-based guidelines on the therapeutic use of repetitive transcranial magnetic stimulation (rTMS): an update (2014-2018). Clin Neurophysiol 2020; 131: 474-528.

25. Lefaucheur JP, André-Obadia N, Poulet E, Devanne H, Haffen E, Londero A, et al. French guidelines on the use of repetitive transcranial magnetic stimulation (rTMS): safety and therapeutic indications. Neurophysiol Clin 2011; 41: 221-295 [Article in French].

26. McClintock SM, Reti IM, Carpenter LL, McDonald WM, Dubin M, Taylor SF, et al.; National Network of Depression Centers rTMS Task Group; American Psychiatric Association Council on Research Task Force on Novel Biomarkers and Treatments. Consensus recommendations for the clinical application of repetitive transcranial magnetic stimulation (rTMS) in the treatment of depression. J Clin Psychiatry 2018; 79: $16 c s 10905$.

27. Lee J, Choi BH, Oh E, Sohn EH, Lee AY. Treatment of Alzheimer's disease with repetitive transcranial magnetic stimulation combined with cognitive training: a prospective, randomized, double-blind, placebo-controlled study. J Clin Neurol 2016; 12: 57-64

28. Dong X, Yan L, Huang L, Guan X, Dong C, Tao H, et al. Repetitive transcranial magnetic stimulation for the treatment of Alzheimer's disease: a systematic review and meta-analysis of randomized controlled trials. PLoS One 2018; 13: e0205704.

29. Lin Y, Jiang WJ, Shan PY, Lu M, Wang T, Li RH, et al. The role of repetitive transcranial magnetic stimulation (rTMS) in the treatment of cognitive impairment in patients with Alzheimer's disease: a systematic review and meta-analysis. J Neurol Sci 2019; 398: 184-191. 
30. Chou YH, Ton That V, Sundman M. A systematic review and meta-analysis of rTMS effects on cognitive enhancement in mild cognitive impairment and Alzheimer's disease. Neurobiol Aging 2020; 86: 1-10.

31. Wang X, Mao Z, Ling Z, Yu X. Repetitive transcranial magnetic stimulation for cognitive impairment in Alzheimer's disease: a meta-analysis of randomized controlled trials. J Neurol 2020; 267: 791-801.

32. Antczak J, Rusin G, Słowik A. Transcranial magnetic stimulation as a diagnostic and therapeutic tool in various types of dementia. J Clin Med 2021; 10: 2875.

33. Leung A, Donohue M, Xu R, Lee R, Lefaucheur JP, Khedr EM, et al. rTMS for suppressing neuropathic pain: a meta-analysis. J Pain 2009; 10: 1205-1216.

34. Jin Y, Xing G, Li G, Wang A, Feng S, Tang Q, et al. High frequency repetitive transcranial magnetic stimulation therapy for chronic neuropathic pain: a meta-analysis. Pain Physician 2015; 18: E1029-1046.

35. Turton A, Wroe S, Trepte N, Fraser C, Lemon RN. Contralateral and ipsilateral EMG responses to transcranial magnetic stimulation during recovery of arm and hand function after stroke. Electroencephalogr Clin Neurophysiol 1996; 101: 316-328.

36. Byrnes ML, Thickbroom GW, Phillips BA, Wilson SA, Mastaglia FL. Physiological studies of the corticomotor projection to the hand after subcortical stroke. Clin Neurophysiol 1999; 110: 487-498.

37. Heald A, Bates D, Cartlidge NE, French JM, Miller S. Longitudinal study of central motor conduction time following stroke. 2. Central motor conduction measured within $72 \mathrm{~h}$ after stroke as a predictor of functional outcome at 12 months. Brain 1993; 116: 1371-1385.

38. Catano A, Houa M, Caroyer JM, Ducarne H, Noël P. Magnetic transcranial stimulation in non-haemorrhagic sylvian strokes: interest of facilitation for early functional prognosis. Electroencephalogr Clin Neurophysiol 1995; 97: 349-354.

39. Escudero JV, Sancho J, Bautista D, Escudero M, López-Trigo J. Prognostic value of motor evoked potential obtained by transcranial magnetic brain stimulation in motor function recovery in patients with acute ischemic stroke. Stroke 1998; 29: 1854-1859.

40. Bembenek JP, Kurczych K, Kłysz B, Cudna A, Antczak J, Członkowska A. Prediction of recovery and outcome using motor evoked potentials and brain derived neurotrophic factor in subacute stroke. J Stroke Cerebrovasc Dis 2020; 29: 105202.

41. Cicinelli P, Traversa R, Rossini PM. Post-stroke reorganization of brain motor output to the hand: a 2-4 month follow-up with focal magnetic transcranial stimulation. Electroencephalogr Clin Neurophysiol 1997; 105: 438-450.

42. Traversa R, Cicinelli P, Bassi A, Rossini PM, Bernardi G. Mapping of motor cortical reorganization after stroke. A brain stimulation study with focal magnetic pulses. Stroke 1997; 28: 110-117.

43. Trompetto C, Assini A, Buccolieri A, Marchese R, Abbruzzese G. Motor recovery following stroke: a transcranial magnetic stimulation study. Clin Neurophysiol 2000; 111: 1860-1867.

44. Liepert J, Storch P, Fritsch A, Weiller C. Motor cortex disinhibition in acute stroke. Clin Neurophysiol 2000; 111: 671-676.

45. Lefaucheur JP, André-Obadia N, Antal A, Ayache SS, Baeken C, Benninger DH, et al. Evidence-based guidelines on the therapeutic use of repetitive transcranial magnetic stimulation (rTMS). Clin Neurophysiol 2014; 125: 2150-2206.

46. Baethge C, Goldbeck-Wood S, Mertens S. SANRA - a scale for the quality assessment of narrative review articles. Res Integr Peer Rev 2019; 4: 5.

47. Zewdie E, Ciechanski P, Kuo HC, Giuffre A, Kahl C, King R, et al. Safety and tolerability of transcranial magnetic and direct current stimulation in children: Prospective single center evidence from 3.5 million stimulations. Brain Stimul 2020; 13: 565-575.

48. Nemanich ST, Chen CY, Chen M, Zorn E, Mueller B, Peyton C, et al. Safety and feasibility of transcranial magnetic stimulation as an exploratory assessment of corticospinal connectivity in infants after perinatal brain injury: an observational study. Phys Ther 2019; 99: 689-700.

49. Eyre JA, Taylor JP, Villagra F, Smith M, Miller S. Evidence of activity-dependent withdrawal of corticospinal projections during human development. Neurology 2001; 57: 1543-1554.

50. Nathan PW, Smith M, Deacon P. Vestibulospinal, reticulospinal and descending propriospinal nerve fibres in man. Brain 1996; 119: 1809-1833.

51. Nezu A, Kimura S, Takeshita S, Tanaka M. Functional recovery in hemiplegic cerebral palsy: ipsilateral electromyographic responses to focal transcranial magnetic stimulation. Brain Dev 1999; 21: 162-165.

52. Eyre JA. Corticospinal tract development and its plasticity after perinatal injury. Neurosci Biobehav Rev 2007; 31: 1136-1149.

53. Staudt M, Gerloff C, Grodd W, Holthausen H, Niemann G, Krägeloh-Mann I. Reorganization in congenital hemiparesis acquired at different gestational ages. Ann Neurol 2004; 56: 854-863.

54. Guzzetta A, Bonanni P, Biagi L, Tosetti M, Montanaro D, Guerrini R, Cioni G. Reorganisation of the somatosensory system after early brain damage. Clin Neurophysiol 2007; 118: 1110-1121.

55. Kirton A, Chen R, Friefeld S, Gunraj C, Pontigon AM, Deveber G. Contralesional repetitive transcranial magnetic stimulation for chronic hemiparesis in subcortical paediatric stroke: a randomised trial. Lancet Neurol 2008; 7 : 507-513.

56. Kirton A, Deveber G, Gunraj C, Chen R. Cortical excitability and interhemispheric inhibition after subcortical pediatric stroke: plastic organization and effects of rTMS. Clin Neurophysiol 2010; 121: 1922-1929.

57. Holmström L, Vollmer B, Tedroff K, Islam M, Persson JK, Kits A, et al. Hand function in relation to brain lesions and corticomotor-projection pattern in children with unilateral cerebral palsy. Dev Med Child Neurol 2010; 52: 145-152.

58. Mackey A, Stinear C, Stott S, Byblow WD. Upper limb function and cortical organization in youth with unilateral cerebral palsy. Front Neurol 2014; 5: 117. 
59. Baranello G, Rossi Sebastiano D, Pagliano E, Visani E, Ciano C, Fumarola A, et al. Hand function assessment in the first years of life in unilateral cerebral palsy: correlation with neuroimaging and cortico-spinal reorganization. Eur J Paediatr Neurol 2016; 20: 114-124.

60. Zewdie E, Damji O, Ciechanski P, Seeger T, Kirton A. Contralesional corticomotor neurophysiology in hemiparetic children with perinatal stroke. Neurorehabil Neural Repair 2017; 31: 261-271.

61. Carneiro MIS, Russo C, Masson R, Rossi Sebastiano D, Baranello G, Turati C, Bolognini N. Motor learning in unilateral cerebral palsy and the influence of corticospinal tract reorganization. Eur J Paediatr Neurol 2020; 27: 49-59.

62. Rich TL, Nemanich S, Chen CY, Sutter EN, Feyma T, Krach LE, Gillick BT. Ipsilateral corticospinal tract excitability contributes to the severity of mirror movements in unilateral cerebral palsy: a case series. Clin EEG Neurosci 2020; 51: 185-190.

63. Netz J, Lammers T, Hömberg V. Reorganization of motor output in the non-affected hemisphere after stroke. Brain 1997; 120: 1579-1586.

64. Eyre JA, Miller S, Clowry GJ, Conway EA, Watts C. Functional corticospinal projections are established prenatally in the human foetus permitting involvement in the development of spinal motor centres. Brain 2000; 123: 51-64.

65. Mailleux L, Simon-Martinez C, Radwan A, Blommaert J, Gooijers J, Wenderoth N, et al. White matter characteristics of motor, sensory and interhemispheric tracts underlying impaired upper limb function in children with unilateral cerebral palsy. Brain Struct Funct 2020; 225: 1495-1509.

66. Tekgul H, Saz U, Yilmaz S, Polat M, Aktan G, Kose T, et al. A transcranial magnetic stimulation study for the investigation of corticospinal motor pathways in children with cerebral palsy. J Clin Neurosci 2020; 78: 153-158.

67. Islam M, Nordstrand L, Holmström L, Kits A, Forssberg H, Eliasson AC. Is outcome of constraint-induced movement therapy in unilateral cerebral palsy dependent on corticomotor projection pattern and brain lesion characteristics? Dev Med Child Neurol 2014; 56: 252-258.

68. Smorenburg AR, Gordon AM, Kuo HC, Ferre CL, Brandao M, Bleyenheuft Y, et al. Does corticospinal tract connectivity influence the response to intensive bimanual therapy in children with unilateral cerebral palsy? Neurorehabil Neural Repair 2017; 31: 250-260.

69. Friel KM, Ferre CL, Brandao M, Kuo HC, Chin K, Hung YC, et al. Improvements in upper extremity function following intensive training are independent of corticospinal tract organization in children with unilateral spastic cerebral palsy: a clinical randomized trial. Front Neurol 2021; 12: 660780.

70. Juenger H, Kuhnke N, Braun C, Ummenhofer F, Wilke M, Walther M, et al. Two types of exercise-induced neuroplasticity in congenital hemiparesis: a transcranial magnetic stimulation, functional MRI, and magnetoencephalography study. Dev Med Child Neurol 2013; 55: 941-951.

71. Marneweck M, Kuo HC, Smorenburg ARP, Ferre CL, Flamand VH, Gupta D, et al. The relationship between hand function and overlapping motor representations of the hands in the contralesional hemisphere in unilateral spastic cerebral palsy. Neurorehabil Neural Repair 2018; 32: 62-72.

72. Maegaki Y, Maeoka Y, Ishii S, Eda I, Ohtagaki A, Kitahara T, et al. Central motor reorganization in cerebral palsy patients with bilateral cerebral lesions. Pediatr Res 1999; 45: 559-567.

73. Kesar TM, Sawaki L, Burdette JH, Cabrera MN, Kolaski K, Smith BP, et al. Motor cortical functional geometry in cerebral palsy and its relationship to disability. Clin Neurophysiol 2012; 123: 1383-1390.

74. Walther M, Juenger H, Kuhnke N, Wilke M, Brodbeck V, Berweck S, et al. Motor cortex plasticity in ischemic perinatal stroke: a transcranial magnetic stimulation and functional MRI study. Pediatr Neurol 2009; 41: 171-178.

75. Friel KM, Kuo HC, Fuller J, Ferre CL, Brandão M, Carmel JB, et al. Skilled bimanual training drives motor cortex plasticity in children with unilateral cerebral palsy. Neurorehabil Neural Repair 2016; 30: 834-844.

76. Kuo HC, Zewdie E, Ciechanski P, Damji O, Kirton A. Intervention-induced motor cortex plasticity in hemiparetic children with perinatal stroke. Neurorehabil Neural Repair 2018; 32: 941-952.

77. Parvin S, Shahrokhi A, Tafakhori A, Irani A, Rasteh M, Mirbagheri MM. Therapeutic effects of repetitive transcranial magnetic stimulation on corticospinal tract activities and neuromuscular properties in children with cerebral palsy. Annu Int Conf IEEE Eng Med Biol Soc 2018; 2018: 2218-2221.

78. Azizi S, Birgani PM, Irani A, Shahrokhi A, Nourian R, Mirbagheri MM. Impact of anti-gravity locomotion (AlterG) training on structure and function of corticospinal tract and gait in children with cerebral palsy. Annu Int Conf IEEE Eng Med Biol Soc 2019; 2019: 126-129.

79. Nemanich ST, Rich TL, Chen CY, Menk J, Rudser K, Chen M, et al. Influence of combined transcranial direct current stimulation and motor training on corticospinal excitability in children with unilateral cerebral palsy. Front Hum Neurosci 2019; 13: 137.

80. Kowalski JL, Nemanich ST, Nawshin T, Chen M, Peyton C, Zorn E, et al. Motor evoked potentials as potential biomarkers of early atypical corticospinal tract development in infants with perinatal stroke. J Clin Med 2019; 8: 1208.

81. Berweck S, Walther M, Brodbeck V, Wagner N, Koerte I, Henschel V, et al. Abnormal motor cortex excitability in congenital stroke. Pediatr Res 2008; 63: 84-88.

82. Heinen F, Kirschner J, Fietzek U, Glocker FX, Mall V, Korinthenberg R. Absence of transcallosal inhibition in adolescents with diplegic cerebral palsy. Muscle Nerve 1999; 22: 255-257.

83. Chen CY, Rich TL, Cassidy JM, Gillick BT. Corticospinal excitability in children with congenital hemiparesis. Brain Sci 2016; 6: 49.

84. Eng D, Zewdie E, Ciechanski P, Damji O, Kirton A. Interhemispheric motor interactions in hemiparetic children with perinatal stroke: clinical correlates and effects of neuromodulation therapy. Clin Neurophysiol 2018; 129: 397-405.

85. Vry J, Linder-Lucht M, Berweck S, Bonati U, Hodapp M, Uhl M, et al. Altered cortical inhibitory function in children with spastic diplegia: a TMS study. Exp Brain Res 2008; 186: 611-618. 
86. Gillick BT, Krach LE, Feyma T, Rich TL, Moberg K, Thomas W, et al. Primed low-frequency repetitive transcranial magnetic stimulation and constraint-induced movement therapy in pediatric hemiparesis: a randomized controlled trial. Dev Med Child Neurol 2014; 56: 44-52.

87. Rich TL, Menk J, Krach LE, Feyma T, Gillick BT. Repetitive transcranial magnetic stimulation/behavioral intervention clinical trial: long-term follow-up of outcomes in congenital hemiparesis. J Child Adolesc Psychopharmacol 2016; 26: 598-605.

88. Rajak BL, Gupta M, Bhatia D, Mukherjee A. Increasing number of therapy sessions of repetitive transcranial magnetic stimulation improves motor development by reducing muscle spasticity in cerebral palsy children. Ann Indian Acad Neurol 2019; 22: 302-307.

89. Kirton A, Andersen J, Herrero M, Nettel-Aguirre A, Carsolio L, Damji O, et al. Brain stimulation and constraint for perinatal stroke hemiparesis: the PLASTIC CHAMPS trial. Neurology 2016; 86: 1659-1667.

90. Marzbani H, Shahrokhi A, Irani A, Mehdinezhad M, Kohanpour M, Mirbagheri MM. The effects of low frequency repetitive transcranial magnetic stimulation on white matter structural connectivity in children with cerebral palsy. Annu Int Conf IEEE Eng Med Biol Soc 2018; 2018: 2491-2494.

91. Zhang W, Zhang S, Zhu M, Tang J, Zhao X, Wang Y, et al. Changes of structural brain network following repetitive transcranial magnetic stimulation in children with bilateral spastic cerebral palsy: a diffusion tensor imaging study. Front Pediatr 2021; 8: 617548.

92. Gupta M, Lal Rajak B, Bhatia D, Mukherjee A. Effect of r-TMS over standard therapy in decreasing muscle tone of spastic cerebral palsy patients. J Med Eng Technol 2016; 40: 210-216.

93. Dadashi F, Shahroki A, Nourian R, Irani A, Molavi M, Rafieenazari Z, et al. The effects of repetitive transcranial magnetic stimulation (rTMS) on balance control in children with cerebral palsy. Annu Int Conf IEEE Eng Med Biol Soc 2019; 2019: 5241-5244.

94. Guo Z, Xing G, He B, Chen H, Ou J, McClure MA, et al. Dynamic modulation of rTMS on functional connectivity and functional network connectivity to children with cerebral palsy: a case report. Neuroreport 2016; 27: 284-288.

95. Gupta M, Bhatia D. Evaluating the effect of repetitive transcranial magnetic stimulation in cerebral palsy children by employing electroencephalogram signals. Ann Indian Acad Neurol 2018; 21: 280-284.

96. Williams PTJA, Jiang YQ, Martin JH. Motor system plasticity after unilateral injury in the developing brain. Dev Med Child Neurol 2017; 59: 1224-1229.

97. Himpens E, Van den Broeck C, Oostra A, Calders P, Vanhaesebrouck P. Prevalence, type, distribution, and severity of cerebral palsy in relation to gestational age: a meta-analytic review. Dev Med Child Neurol 2008; 50: 334-340.

98. Collange Grecco LA, de Almeida Carvalho Duarte N, Mendonça ME, Galli M, Fregni F, Oliveira CS. Effects of anodal transcranial direct current stimulation (tDCS) combined with virtual reality for improving gait in children with spastic diparetic cerebral palsy: a pilot, randomized, controlled, double-blind, clinical trial. Clin Rehabil 2015; 29: 1212-1223.

99. Sabbagh M, Sadowsky C, Tousi B, Agronin ME, Alva G, Armon C, et al. Effects of a combined transcranial magnetic stimulation (TMS) and cognitive training intervention in patients with Alzheimer's disease. Alzheimers Dement 2020; 16: 641-650. 